\title{
6. The Use of Cellulose Azure Agar as a Crude Assay of Both Cellulolytic and Ligninolytic Abilities of Wood-inhabiting Fungi
}

\author{
By R. Greg THORN \\ Center for Microbial Ecology, Michigan State University, \\ East Lansing, MI 48824, U.S.A. \\ (Communicated by Naohide Hiratsuka, M.J. A., Feb. 12, 1993)
}

\begin{abstract}
Based on a study of 185 isolates of corticioid and polyporoid Basidiomycetes, the cellulose azure test provides a simple and effective assay for both cellulolytic and ligninolytic capabilities of fungal cultures. Decolourization of the dye Remazol Brilliant blue $R$, whether or not it has been previously released from the cellulose azure by cellulase, is an indicator of ligninolytic enzymes in a test culture.
\end{abstract}

Key words: Wood decay fungi; cultural studies; techniques; Poly R-478.

Introduction. Studies of wood-inhabiting fungi have for many years included investigations of their enzymatic abilities, particularly with respect to their abilities to degrade wood (reviewed by Bateman 1976, Reese 1977, Crawford 1981, Rayner and Boddy 1988). Among the simpler in vitro assays for decay ability are spot tests of a variety of chemicals that give coloured reactions indicating the production by an agar culture of the ligninolytic enzymes laccase, tyrosinase, lignin peroxidase or manganese peroxidase (Fåhraeus 1949, Lyr 1958, Nobles 1958, Käärik 1965, Harkin and Obst 1973, Clémençon 1977, and Niku-Paavola et al. 1990). Unfortunately, the composition of the agar medium and the age or growth stage of the culture greatly affect the outcome of such tests (Fåhraeus 1952, Hiorth 1965, Schánel 1966, Flodin 1979, Leslie and Leonard 1979, Paranjpe and Chen 1979, Kim et al. 1986, Stenlid and Rayner 1989), rendering them rather unreliable. Glenn and Gold (1983) suggested that the clearing of various polymeric dyes structurally related to lignin compounds could be used as an assay of ligninolytic capability in fungi. The dyes most widely used for this purpose have been Poly B-411 (Glenn and Gold 1983, Chet et al. 1985, Platt et al. 1985, Gold et al. 1988) and Poly R-478 (Ball et al. 1989, Pasti and Crawford 1991, Freitag and Morrell 1992). Poly B-411 is no longer available from the original supplier (Sigma) and decolourization of its replacement, Poly R-478, shows less direct correlation to ligninolytic ability (Pasti and Crawford 1991, Freitag and Morrell 1992). Smith (1977) proposed a simple test for detecting cellulolytic ability in fungal cultures based on the release of the dye Remazol Brilliant blue R (RBBR) from dyed cellulose (modified from Rinderknecht 1967). Highley (1983) and Hegarty et al. (1987) noted that a number of white-rot species caused clearing of the blue dye released from cellulose azure. Ulmer et al. (1984) and Waldner et al. (1988) have used the decolourization of RBBR as a test for ligninolytic ability in fungi, and Pasti and Crawford (1991) have recently correlated its decolourization by Streptomycetes with the ability to degrade lignocellulose. Here I suggest that the cellulose azure test provides a simple and effective assay for both cellulolytic and ligninolytic capabilities of fungal cultures.

Materials and methods. One hundred and eighty-five polyspore or tissue isolates of corticioid and polyporoid fungi (Thorn 1991) were maintained on Difco Bacto potato dextrose agar (PDA), malt extract agar (MEA) and modified Leonian's agar (ML). 
Composition of these and other media used, with the exception of PDA, are listed in Table I. Disks cut with a $5 \mathrm{~mm}$ cork borer from the margin of colonies grown on MEA were used to inoculate all of the bottles or Petri dishes of test media. All media but cellulose azure were autoclaved 20 minutes at $121^{\circ} \mathrm{C}$ and dispensed in approximately $20 \mathrm{ml}$ aliquots into $100 \mathrm{~mm}$ disposable polystyrene Petri dishes. Cellulose azure tubes (modified from Smith 1977) were prepared by dispensing $15 \mathrm{ml}$ of basal medium into $25 \mathrm{ml}$ square flint bottles, autoclaving these 20 minutes at $121^{\circ} \mathrm{C}$, allowing the bottles to cool in an upright position, then aseptically dispensing $0.8 \mathrm{ml}$ of autoclaved overlay medium into each bottle using a repeating pipette (Gilson Pipetman P-1000). The release of the dye from the cellulose azure overlay medium, and its subsequent diffusion into the lower, previously colourless basal medium (see Fig. 1) was used for the assay of cellulose degradation by cellulase (E.C. 3.2.1.4). Decolourization of the RBBR, whether or not it has been released from the cellulose azure, was taken as an indicator of ligninolytic ability (Pasti and Crawford 1991). An alternate test of ligninolytic ability used the clearing of Poly R-478, a polymeric dye with a poly (vinylamine) sulfonate backbone and an anthrapyridone chromophore that has replaced the dyes Poly B-411 and Poly R-481 used for the same purpose by Glenn and Gold (1983). Test bottles and plates were incubated in the dark at $20-24^{\circ} \mathrm{C}$ and reactions recorded after 1, 2, 4 and 6 weeks. All reactions were scored subjectively on a scale from 0 (no reaction) to 5 (complete, or intense).

Colonies grown on PDA, MEA and ML were spot-tested after 6 weeks with $\alpha$-naphthol (0.1M in 95\% ethanol, Käärik 1965), syringaldazine (0.1\% in $95 \%$ ethanol, Marr $1979)$ and guaiacol $(0.1 \mathrm{M}$ in $95 \%$ ethanol, Käärik 1965) as indicators of laccase (E.C. 1.10.3.2), p-cresol (0.1M in 95\% ethanol, Käärik 1965) as an indicator of tyrosinase (E.C. 1.10.3.2, catechol oxidase and E.C. 1.14.18.1, monophenol monooxygenase), and with freshly-prepared $0.4 \% \mathrm{H}_{2} \mathrm{O}_{2}$ on unreactive syringaldazine spot tests (Harkin and Obst 1973) as an indicator of peroxidases (E.C.1.11.1.7). Spots were applied with a medicine dropper and streaked radially from within the colony to well beyond the mycelial margin. Reactions with syringaldazine and $\mathrm{H}_{2} \mathrm{O}_{2}$ were recorded after 5 minutes, and those with guaiacol and $\alpha$-naphthol after one hour.

Results. Remazol Brilliant blue $\mathrm{R}$ was liberated from cellulose azure by 161 of 185 isolates (Fig. 1). In addition to the release of the blue dye from the cellulose, a proportion

Table I. Composition of test media

\begin{tabular}{|c|c|c|c|c|c|c|c|c|}
\hline Ingredient $^{1)}$ & $\mathrm{MEA}^{2)}$ & $\mathrm{ML}^{2)}$ & & $\mathrm{CA}-\mathrm{BM}^{2}$ & & $\mathrm{CA}-\mathrm{OL}^{2)}$ & PR-478 & \\
\hline Agar $^{3)}$ & $20 \mathrm{~g}$ & 20 & $\mathrm{~g}$ & 15 & $\mathrm{~g}$ & $15 \mathrm{~g}$ & 15 & $\mathrm{~g}$ \\
\hline Malt Extract ${ }^{3)}$ & $12.5 \mathrm{~g}$ & 6.25 & $\mathrm{~g}$ & & & $5.0 \mathrm{~g}$ & & \\
\hline Yeast Extract ${ }^{3)}$ & & 1.0 & $\mathrm{~g}$ & 1.0 & $\mathrm{~g}$ & $1.0 \mathrm{~g}$ & 1.0 & $\mathrm{~g}$ \\
\hline $\mathrm{KH}_{2} \mathrm{PO}_{4}$ & & 1.25 & $\mathrm{~g}$ & 1.25 & $\mathrm{~g}$ & & 1.25 & $\mathrm{~g}$ \\
\hline $\mathrm{MgSO}_{4}-7 \mathrm{H}_{2} \mathrm{O}$ & & 0.625 & $\mathrm{~g}$ & 0.625 & $\mathrm{~g}$ & & 0.625 & $5 \mathrm{~g}$ \\
\hline Peptone $^{3)}$ & & 0.625 & $\mathrm{~g}$ & 0.625 & $\mathrm{~g}$ & & & \\
\hline Glucose & & & & & & & 1.0 & $\mathrm{~g}$ \\
\hline Maltose & & 6.25 & $\mathrm{~g}$ & & & & & \\
\hline Cellulose Azure $^{4)}$ & & & & & & $5.0 \mathrm{~g}$ & & \\
\hline Poly R-478 (Sigma) & & & & & & & 0.2 & $\mathrm{~g}$ \\
\hline
\end{tabular}

1) In grams per litre distilled water.

2) $\mathrm{MEA}=$ malt extract agar (Nobles 1948); $\mathrm{ML}=$ modified Leonian's agar (Malloch 1981); CA-BM=cellulose azure basal medium; $\mathrm{CA}-\mathrm{OL}=$ cellulose azure

3) Difco Bacto. overlay; PR-478=Poly R-478 agar.

4) Calbiochem, San Diego, California. 
of the isolates studied (31 of 185) subsequently cleared the dye, so that the lower portion of the agar tube went from clear to blue to clear again. Strong clearing was shown by species of Peniophora and Punctularia, Pulcherricium caeruleum, Dendrocorticium roseocarneum, Amylobasidium, Cerocorticium, Mutatoderma and Eichleriella. An additional 72 isolates showed lesser but noticeable clearing of the dye by 6 weeks. A few isolates, all of Dendrothele, cleared the blue dye in situ without prior release through cellulolysis.

Marked clearing of the polymeric dye Poly R-478 by 6 weeks was seen in 32 of 185 isolates. In most cases, this clearing had been evident from 2 weeks. Most fungi capable of clearing Poly R-478 belonged to Peniophora, but also included both Punctularia atropurpurascens and $P$. strigosozonata, Amylobasidium tsugae, Pulcherricium caeruleum, Vararia gallica, and some isolates of Dendrothele, Eichleriella, Mutatoderma, and Vuilleminia comedens. Less dramatic clearing was difficult to detect by eye, perhaps because the water-soluble Poly R-478 dye diffused readily from the margins of plates into areas where it was being cleared.

The reactions to syringaldazine $\alpha$-naphthol, and guaiacol were similar within most test isolates. Some isolates developed most strongly positive reactions on ML, others on PDA, and still others on MEA. Occasional isolates developed a more strongly positive reaction to guaiacol or $\alpha$-naphthol than to syringaldazine. Species of Dendrocorticium, Dendrothele, Peniophora, Punctularia and Vuilleminia gave strong positive reactions for laccase, whereas most isolates of Corticium and Aleurodiscus and its segregate genera gave weak reactions. Because of the overlapping substrate specificities of laccase and peroxidase, it was impossible to test for peroxidase in the presence of laccase. Use of a laccase inhibitor (Murao et al. 1992) might have overcome this problem. Previous reports (e.g. Lyr 1958) have suggested that the colour of the reaction product intensifies following application of $\mathrm{H}_{2} \mathrm{O}_{2}$ in the presence of peroxidase, but no such intensification was visible in any case where a positive reaction (indicating laccase) was first obtained. Peroxidase could be demonstrated in only one species, Pulcherricium caeruleum, in which laccase is lacking

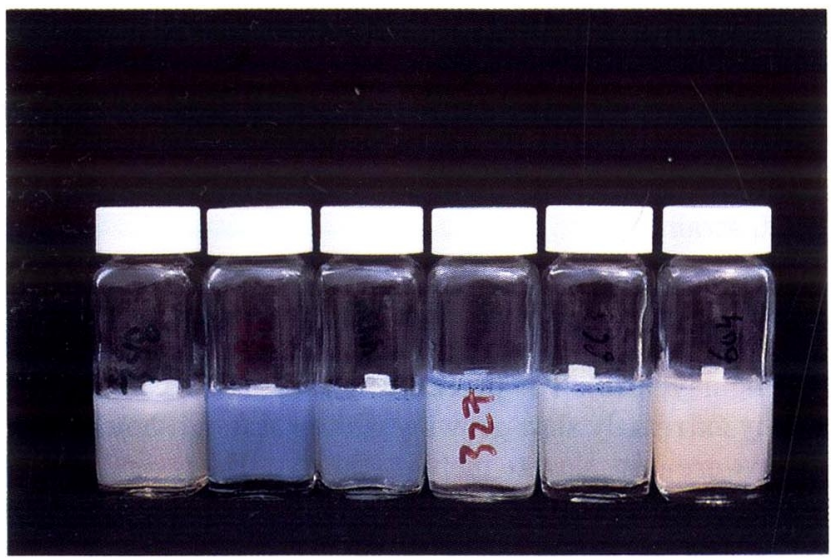

Fig. 1. Reactions in cellulose azure test after 6 weeks. Left to right, complete mobilization (scored as $5+$ ) followed by complete clearing $(5+)$ of RBBR by Mutatoderma populneum 348; complete mobilization (5+) of RBBR without clearing (0) by Aleurodiscus amorphus 388; partial mobilization (3+) by Polyporus pseudobetulinus 444w; slight mobilization (1+) by Aleurodiscus sp. 327; no mobilization or clearing (0) by Dendrothele microspora 668; and clearing $(4+)$ without mobilization $(0)$ by Dendrothele maculata 604. 
Table II. Product-moment correlation $\left(\mathrm{r}^{1)}\right)$ of 8 physiological characters ${ }^{2)}$

\begin{tabular}{l|cccccccc}
\hline & 1 & 2 & 3 & 4 & 5 & 6 & 7 & 8 \\
\hline 1 & 1.00 & & & & & & & \\
2 & 0.70 & 1.00 & & & & & & \\
3 & 0.69 & 0.48 & 1.00 & & & & & \\
4 & 0.39 & 0.72 & 0.31 & 1.00 & & & & \\
5 & 0.11 & 0.31 & 0.18 & 0.29 & 1.00 & & & \\
6 & 0.14 & 0.38 & 0.16 & 0.33 & 0.88 & 1.00 & & \\
7 & 0.16 & 0.36 & 0.19 & 0.31 & 0.87 & 0.92 & 1.00 & \\
8 & 0.37 & 0.37 & 0.40 & 0.25 & 0.31 & 0.34 & 0.37 & 1.00 \\
\hline
\end{tabular}

1) Calculated for 183 strains with complete data using NTSYS-PC (Rohlf 1988).

2) Character List: 1=Mobilization of Remazol Blue; $2=$ Clearing of Remazol Blue; $3=$ Growth on Poly R-478; $4=$ Clearing of Poly R-478; $5=$ Reaction to Syringaldazine; $6=$ Reaction to $\alpha$-Naphthol; $7=$ Reaction to Guaiacol; $8=$ Reaction to p-Cresol.

(Boidin 1958). This species also gave strong positive reactions for tyrosinase. Strong positive reactions were found with p-cresol in 15 isolates, including Amylobasidium, Cryptoporus, several Peniophora species and Vuilleminia comedens. Positive reactions for tyrosinase rarely developed on MEA.

Mobilization of RBBR was correlated to growth rate on Poly $\mathrm{R}-478$ medium $(\mathrm{r}=0.69)$ and to subsequent clearing of RBBR ( $r=0.70$; Table II). Clearing of RBBR and Poly R-478 were correlated $(\mathrm{r}=0.72)$ but not strongly correlated to reactions indicating laccase or tyrosinase. Positive reactions for laccase and tyrosinase were not strongly correlated (Table II), but Pulcherricium caeruleum and Sistotrema eximum were the only species exhibiting tyrosinase in the absence of laccase.

Discussion. According to Highley (1988), release of dye from cellulose azure is not a guarantee of ability to degrade native cellulose, since the cellulose used in cellulose azure is acid-swollen and more susceptible to degradation. However, the cellulose azure test provides a rapid and generally reliable qualitative and semiquantitative indicator of the cellulose degrading abilities of a large number of isolates, although biased by the growth rate of the test strain.

Highley (1973) reported that white-rot fungi produce cellulases for both carboxymethyl cellulose $\left(\mathrm{C}_{\mathrm{X}}\right)$ and microcrystaline cellulose $\left(\mathrm{C}_{1}\right)$. These enzymes are completely repressed by the presence of simple sugars, but enhanced by $0.5 \%$ peptone, asparagine or yeast extract (Highley 1973). The presence of $0.5 \%$ malt extract in the upper, dyed layer could explain why extremely slow-growing white-rot fungi showed no evidence of cellulase in these tests, or were very slow to mobilize the dye. However, one fast-growing isolate of Hyphoderma typhicola that tested strongly positive for laccase showed no ability to clear Poly R-478 or to release or clear remazol blue. Although this species is a member of a genus known to cause white-rot, its ability to cause wood decay is unknown.

Brown-rot fungi, with the exception of the Coniophoraceae (Nilsson and Ginns 1979), produce only $\mathrm{C}_{\mathrm{X}}$ (Highley 1973). This enzyme is produced in presence of simple sugars and absent without them, but is considerably repressed in certain species by $0.5 \%$ peptone, asparagine or yeast extract (Highley 1973). The presence of $0.1 \%$ yeast extract in both upper and basal layers might have repressed cellulase activity in the brown-rot fungi that were included, but all of them eventually tested positive for cellulase. Of the 4 species of brown-rot fungi tested, Serpula himantioides produced considerable clearing and 
Leucogyrophana romellii produced slight clearing of RBBR.

Lignin peroxidases of Phanerochaete chrysosporium are produced during secondary metabolism, under conditions of low nitrogen availability (Jeffries et al. 1981, Kirk and Farrell 1987). Nitrogen appears not to be as inhibitory to the ligninolytic enzyme systems of Pleurotus ostreatus (Platt et al. 1985). Yeast extract and peptone present in the cellulose azure tubes may have been inhibitory to the ligninolytic enzymes of some of the test fungi, and not to others. However, in tubes that had been negative after 6 weeks there was still no decolourization of RBBR after 12 weeks incubation, by which time it was expected that the initial supply of these nitrogenous compounds would have been exhausted.

Freitag and Morrell (1992) have suggested using the degradation of Poly R-478 as an assay of ligninolytic ability in fungi, although they reported that Asperigillus niger, Gliocladium virens, and 16 brown-rot fungi also decolourized the dye. In this study, the brown-rot fungus Serpula himantioides cleared RBBR but not Poly R-478. There was moderately close correlation between clearing of cellulose azure (RBBR) and clearing of Poly R-478, but many more isolates showed some clearing of RBBR than of Poly R-478, giving better correlation to what is known of the decay abilities of the fungi tested. As noted by Freitag and Morrell (1992), cultures that have lost vigour through prolonged culture ("attenuated strains") are no longer capable of degrading Poly R-478 or RBBR. This supports the findings of Pasti and Crawford (1991) that clearing of RBBR is a good indicator of ligninolytic ability. As such, it is certainly more convenient to use the cellulose azure test for both cellulase and ligninolytic capabilities, than to use a separate Poly R-478 test for the latter, and the results are more definite than those of the Poly R-478 test. The cellulose azure assay may be particularly valuable for screening large numbers of isolates for decay abilities. However, a few isolates of Dendrothele caused clearing of both RBBR (without cellulolysis) and Poly R-478. These species occur not on wood but on thick, tannin-rich bark of hardwood trees, particularly Quercus (Lemke 1964), suggesting that degradation of these dyes may not directly indicate ability to decay wood.

Acknowledgments. This work was done at the University of Toronto under D. W. Malloch, and was supported by an NSERC postgraduate scholarship to RGT and NSERC operating grants to DWM.

\section{References}

Ball, A. S., Betts, W. B., and McCarthy, A. J. (1989): Appl. Environ. Microbiol., 55, 1642-1644.

Bateman, D. F. (1976): Plant Cell Wall Hydrolysis, Ch. 5 (eds. J. Friend, and D. R. Threlfall). Biochemical Aspects of Plant-Parasite Relationships. Ann. Proc. Phytochem., Soc., 13, Academic Press, London, pp. 79-103.

Boidin, J. (1958): Essai biotaxonomique sur les Hydnés résupinés et les Corticiés. Rev. Mycol. Mem. hors Ser. 6, 1-388.

Chet, I., Trojanowski, J., and Hüttermann, A. (1985): Microbios Lett., 29, 37-43.

Clémençon, H. (1977): Mycologia, 69, 416-417.

Crawford, R. L. (1981): Lignin Biodegradation and Transformation. John Wiley and Sons, New York.

Fåhraeus, G. (1949): Roy. Agric. Colleg. Sweden Ann., 16, 618-629.

- (1952): Phys. Plant., 5, 284-291.

Flodin, K. (1979): Eur. J. For. Path., 9, 1-6.

Freitag, M., and Morrell, J. J. (1992): Can. J. Microbiol., 38, 811-822.

Glenn, J. K., and Gold, M. H. (1983): Appl. Environ. Microbiol., 45, 1741-1747.

Gold, M. H., Glenn, J. K., and Alic, M. (1988): Methods Enzymol., 161, 74-78. 
Harkin, J. M., and Obst, J. R. (1973): Experientia, 29, 381-387.

Hegarty, B. et al. (1987): Holzforschung, 41, 265-269.

Highley, T. L. (1973): Wood and Fiber, 5, 50-58.

- (1983): Mater. u. Org., 18, 161-170. (1988): Holzforschung, 42, 211-216.

Hiorth, J. (1965): Meddeleser fra det Norske Skogforsöksvesen, 20, 249-272.

Jeffries, T. W., Choi, S., and Kirk, T. K. (1981): Appl. Environ. Microbiol., 42, 290-296.

Käärik, A. (1965): Studia forest. Suec., 31, 1-38.

Kim, K.-J., Shin, K.-S., and Hong, S.-W. (1986): Korean J. Mycol., 14, $43-47$.

Kirk, T. K., and Farrell, R. L. (1987): Annu. Rev. Microbiol., 41, 465-505.

Lemke, P. A. (1964): Can. J. Bot., 42, 723-768.

Leslie, J. F., and Leonard, T. J. (1979): Mycologia, 71, 1082-1085.

Lyr, H. (1958): Planta, 50, 359-370.

Malloch, D. W. (1981): Moulds: Their isolation, cultivation, and identification. University of Toronto Press, Toronto.

Marr, C. D. (1979): Mycotaxon, 9, 244-276.

Murao, S. et al. (1992): Biosci. Biotech. Biochem., 56, 987-988.

Niku-Paavola, M. L., Raaska, L., and Itävaara, M. (1990): Mycol. Res., 94, 27-31.

Nilsson, T., and Ginns, J. (1979): Mycologia, 71, 170-177.

Nobles, M. K. (1948): Can. J. Res. C, 26, 281-431. (1958): Can. J. Bot., 36, 91-99.

Paranjpe, M. S., and Chen, P. K. (1979): Mycologia, 71, 469-478.

Pasti, M. B., and Crawford, D. L. (1991): Can. J. Microbiol., 37, 902-907.

Platt, M., Hadar, Y., and Chet, I. (1985): Appl. Microbiol. Biotechnol., 21, 394-396.

Rayner, A., and Boddy, L. (1988): Fungal Decomposition of Wood. John Wiley and Sons, Chichester and New York.

Reese, E. T. (1977): Degradation of Polymeric Carbohydrates by Microbial Enzymes (eds. F. A. Loewus and V. C. Runeckles). The Structure, Biosynthesis and Degradation of Wood. Plenum Press, New York, pp. 311-367.

Rinderknecht, H., Wilding, P., and Haverback, B. J. (1967): Experientia, 23, 805.

Rohlf, F. J. (1988): NTSYS-pc: Numerical taxonomy and multivariate analysis system, version 1.50. Exeter Publishing Ltd., Setauket, New York.

Schánel, L. (1966): Biol. Plantarum, 8, 292-296.

Smith, R. E. (1977): Appl. Environ. Microbiol., 33, 980-981.

Stenlid, J., and Rayner, A. D. M. (1989): New Phytol., 113, 245-258.

Thorn, R. G. (1991): Taxonomic studies of cultures of selected Corticiaceae (Basidiomycota). Ph.D. Thesis, University of Toronto.

Ulmer, D., Leisola, M. S. A., and Fischer, A. (1984): J. Biotechnol., 1, 13-24.

Waldner, R., Leisola, M. S. A., and Fiechter, A. (1988): Appl. Microbiol. Biotechnol., 29, $400-407$. 